\title{
Perceptions of Patients Regarding Quality Nursing Care (QNC) at a Tertiary Care Hospital in Karachi, Pakistan
}

\section{Ayyub R*, Kanji Z, Dias J and Roshan R}

Aga Khan University School of Nursing \& Midwifery Karachi, Pakistan

*Corresponding author: Ayyub R, Aga Khan University School of Nursing \& Midwifery Karachi, Pakistan, Tel: 009-2342-0504435; E-mail: rehanaayub@hotmail.com Received date: October 25, 2015; Accepted date: December 28, 2015; Published date: December 30, 2015

Copyright: (C2015 Ayyub R, et al. This is an open-access article distributed under the terms of the Creative Commons Attribution License, which permits unrestricted use, distribution, and reproduction in any medium, provided the original author and source are credited.

\begin{abstract}
Background: Patients' experiences regarding the quality of care continue to be a hot topic of discussion in the healthcare industry. Exploring the quality of nursing care from the patients' perspectives is a vital element of quality evaluation. The purpose of this study was to explore the patients' perspectives regarding quality nursing care.

Methodology: A qualitative descriptive exploratory design was used. A total of twelve participants were recruited from one medical and one surgical unit at a tertiary care hospital in Karachi, Pakistan. Purposive sampling was used to select the participants. Data was collected through semi-structured interviews. A thematic analysis approach was used for data analysis.
\end{abstract}

Results: Data analysis generated three main themes: (1) meaning of QNC, (2) characteristics of nurses, and (3) participants' recommendations.

Conclusion: Nursing care continues to be the foundation of healthcare and QNC could have a great effect on patients' positive outcome of recovery and well-being. The study also provided vital implications for nursing administrators, practicing nurses, nursing, education, and research.

Keywords: Quality; Nursing care; Patients' perceptions

\section{Introduction}

Maintaining quality care is a fundamental responsibility of any healthcare organization. Providing high-quality care and ensuring patients' complete satisfaction is a challenge that healthcare organizations face globally. Exploring the quality of nursing care from the patients' perspective is an essential part of quality evaluation.

Literature supports the importance of exploring the patients' perspectives of quality nursing care in order to fulfill patients' needs and expectations at a satisfactory level $[1,2]$. Zhao and Akkadechanunt (2011) define Quality Nursing Care (QNC) as "the degree of excellence observed in nursing care delivery to patients, and it comprises of five categories, which are: staff characteristics, care-related activities, preconditions for care, environment, and progress of the nursing process as perceived by patients". "Examining the quality of nursing care from the patients' perspective is an important element in quality evaluation, since patients admitted to hospital, have high expectations of the health care system" [3]. Moreover, patients as customers can be considered as vital sources of information for the evaluation of existing care. But, in order to provide quality nursing care to the patients, healthcare organizations need to understand their perception. Patients' perceptions about quality nursing care are becoming progressively important in this competitive era. Globally at all levels when discussing the quality of care, evaluating patients' opinions about the quality of care has become a subject of increasing interest [4].

\section{Methodology}

\section{Study design}

A qualitative exploratory descriptive design was used. The purpose was to explore the patients' perceptions of Quality Nursing Care (QNC) in order to gain an in depth, and detailed understanding of it.

\section{Study population and setting}

The study population was Pakistani patients, aged 18 years and above, admitted for a minimum of three days at a tertiary care hospital. The setting for this study was the general medical and surgical wards at a tertiary care hospital in Karachi, Pakistan. Two units; one from medical and one from surgical were selected, and each of these had sixty beds.

\section{Sample and Sampling}

The sample size for this study was 12 participants. $50 \%$ participates were males and 50\% were females and age range was 25-75 years. The purposive sampling technique was used to select the participants in this study.

\section{Data collection}

The data was collected through semi-structured interview. Semistructured interviews are used to explore a list of topics. Researchers prepare a written topic guide, which is a list of questions to be covered with each participant [5]. This data collection source was appropriate for the exploration of perceptions of QNC from the participants. 
Page 2 of 5

\section{Inclusion criteria}

The criteria for inclusion of participants in this study was as follows: 1) Hospitalized for a minimum of three days, 2) Male or Female, 3) Age 18 years or older, 4) Able to communicate in Urdu and/or English, 5) Able to share his/her experiences of nursing care received at the hospital, and 6) Willing to give an audio taped interview.

\section{Exclusion criteria}

Critically ill patients, children, and psychiatric patients are not able to provide correct information. Hence, all critical care areas including, Intensive Care Unit (ICU), Cardiac Intensive Care Unit (CICU), Cardiac Care Unit (CCU), and Special Care Unit (SCU), and Peadiatric, and Psychiatric wards were excluded from the study. Private wards were also excluded as the nurse-patient ratio there is different from the general wards.

\section{Ethical considerations}

Permission was taken from the Ethical Review Committee (ERC) of the institution in which the study was conducted. The participants' right of autonomy was maintained by taking informed consent from each participant.

\section{Data analysis}

In this study the method described by Braun and Clarke (2006) was used to for identifying, analyzing, and reporting patterns (themes) within data. The process of data analysis consisted of six steps; i) Becoming familiar with the data, ii) Generating initial codes, iii) Searching for themes, iv) Reviewing themes, v) Defining themes and naming them vi) and finally Producing a report [6].

\section{Results}

Three main themes and eight subthemes emerged were: I. "Meaning of QNC", and sub themes a) Receiving physical care with respect, b) Responding promptly, and c) Meeting expectations. II. "Nurses' Characteristics", and sub themes a) Personal characteristics b) Providing information, and c) Competent clinical skills. III. "Participants' Recommendations" and subthemes a) Management level, b) Nurses level.

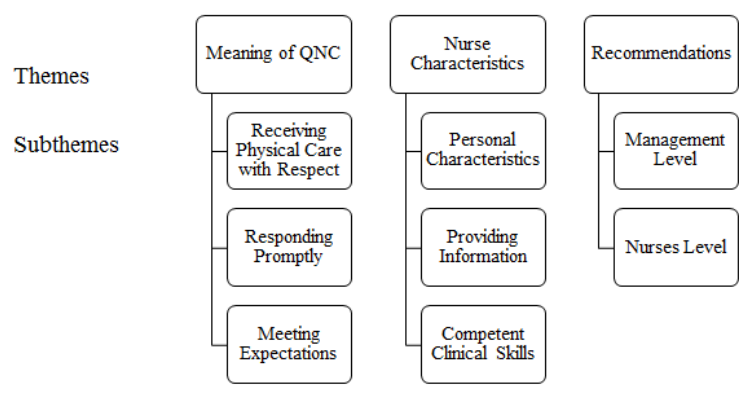

Figure 1: Schematic framework of main themes and sub-themes of QNC.

\section{Meaning of QNC}

According to the perceptions of patients the first main theme was "Meaning of QNC" which included three sub themes (i) Receiving physical care with respect, (ii) Responding promptly, and (iii) Meeting expectations.

\section{Receiving physical care with respect}

Most of the participants considered that receiving physical care with respect was a fundamental element of quality nursing care. Participant F described that, "Quality nursing care is when a nurse gives complete care to the patient; meaning fulfills all patients' physical needs in time, with respect and care".

\section{Responding promptly}

This subtheme refers to the response of the nursing staff to the patients without any delays. The participants described responding promptly as nurses' response time to the participants' call bell. Most of the patients viewed prompt care as quality care, as a majority of them received delayed care from the nurses. Some participants identified that there was more delay in the night and evening shifts as compared to the morning shifts. Participant $\mathrm{K}$ verbalized the delay especially during the night shifts:

When I call [ring] the bell, they do not come on time. I think good care is to come and attend [to] patient on time. Especially at night I do not see any nurse visits frequently... Day time, especially morning shift nurses come on time and care is much better, but in the night, they come very late. Once I wanted to go to the washroom, I called and I waited and the nurse came very late. How can I go to the washroom alone?

\section{Meeting expectations}

The subtheme "meeting expectations" refers to the participants' expectations from nurses to provide quality nursing care. If these expectations were met, the participants were satisfied with the provided care and labeled it as quality nursing care. Participants mentioned this by comparing their previous experiences during hospitalization with the current admission. They commented that previously the nurses followed standards. For example, according to participant C,

They have to maintain the standards and previously they used to do this, but improvement is needed to maintain the quality. Although the hospital is JCIA certified and all that...So things [policies] are there, standards are there, but they [nurses] are not following [standards].

According to participant E, "this time when I got admitted, I did not like any type of care. Even two and a half years back their [nurses] attitude was good...but this time I did not like any form of care".

\section{Nurse Characteristics}

This theme of nurse characteristics refers to the nurses' personal qualities and the clinical skills necessary for professional practice. The abstracted meaning of nurse characteristics from the participants' interview can be described under the three main subthemes: personal characteristics, providing information, and competent clinical skills. 
Page 3 of 5

\section{Personal characteristics}

This sub theme emerged from the participants' perceptions of good qualities that nurses must possess in order to provide quality nursing care. Most participants identified both positive and negative qualities of nurses that they had experienced, and some of them recommended qualities that they expected of nurses for providing QNC. The importance of nurses having positive attitude and keeping a smiling face was commonly identified by most participants as a positive characteristic. Participant K, relayed that, Here, in hospital I found that nurses keep a smile on their faces even if they are tired. Angry faces make your mood low. For quality care I would say that when nurses care patients with a smiling face, it makes a person feel good.

A few participants wished to see nurses with some sense of humor while delivering care. For example, participant K stressed that, Quality care I would say is when nurses care for patients with a smiling face...and some sense of humor. Being a patient is a depressing feeling, and in the hospital the environment should be in a way that patients feel calm...in doctors and nurses there should be some sense of humor when dealing with patients.

\section{Providing information}

This sub-theme refers to the nurses providing theoretical or clinical information and answering to patients' pertinent questions. Participant F stated, "Nurses do explain a procedure before performing on the patient". Similarly, participant $\mathrm{K}$ also shared his views, "here [in hospital] they [nurses] explain everything to the patient. When I was admitted, the nurse explained the ward routine and then the procedure and I felt very good...they are well trained and they know about medicine and patients' treatment".

However, a few participants expressed that the nurses do not answers the patients' questions related to medical treatment. They believed that the nurses' job was to look after the patients, but they are not knowledgeable. Participant $\mathrm{H}$ shared, the negative side is that when there is a question [related to medical treatment] in a patient's mind and when I question directly they say that the doctor will tell you. It means that the nurses are not in the picture completely. I mean they are here to do [only] monitoring part of their job.

\section{Competent clinical skills}

This sub-theme refers to the nurses' abilities to perform the clinical skills proficiently. Some participants viewed clinical skills as important characteristics the nurse must have in order to provide QNC. Most participants used the word 'competent' and 'expert'. Participant $\mathrm{C}$ mentioned, "Two nurses, $\mathrm{X}$ and $\mathrm{X}$, were experts in passing Intra Venous (IV) cannula. They are competent and confident". Stressing the need for expert nurses, participant F expressed that, "nurses need to be experts in their skills and also competent in their profession". The above quotes reveal that nurses' expertise leads to minimizing pain and discomfort of procedures and ultimately enhances QNC.

\section{Recommendations}

The study participants provided some recommendations that could be implemented at the management and at the nurses' level in order to improve the standards of nursing care.

\section{Management level}

At this level, the participants gave the following recommendations:

Increasing staffing: Most participants recommended increasing the number of staff. In addition, most participants felt that nurses seemed to be generally good but they were few in number, hence, they could not attend to the patients' needs on time. The nurse-patient ratio is $1: 10$ in the general ward, and the participants suggested nurse-patient ratio to be 1:5 in each unit. Participant B mentioned, "In my view the problem is that I cannot stay here [in hospital] without my personal attendant and I have a reason for that, which is "Staff cannot attend to patients". Staff [nurses] are not bad, they are good but they are very few [in number]".

Arranging training for the staff: One participant suggested training sessions for nurses to update their knowledge and skills. While participant $\mathrm{C}$ recommended refresher courses and advised that nurses should practice the IV cannula insertion more.

Ensuring environmental cleanliness: Some participants recommended ensuring environmental cleanliness which included cleanliness of wards, cupboards, and washrooms. Participant B claimed that, "cleanliness is declining as compared to 10-15 years ago. Cleanliness in bathrooms/washrooms is not maintained and supplies are not sufficient, e.g., insufficient toilet rolls".

The participants also identified the torn curtains in the wards without hooks. While participant C strongly felt that, Now cleanliness is poor here. Ten to fifteen years ago I used to come here to see my friend who was admitted, at that time cleanliness was good, one could see the cleanliness. Now, cleanliness is not good. One thing right now I can show you [researcher]; look at that cabinet; how many telephone numbers are written, right? This is not good, look at the curtains; you can see many hooks in the curtains are broken.

Improving food variety: Some participants shared their experiences regarding hospital food. They experienced a certain kind of smell in the food and thought that the plastic utensils for food may be causing the smell. Further, the participants mentioned that they lost their appetite due to the smell of food. Some participants disliked the taste of food as well. Participant D shared that, The meals come in plastic utensils and as soon as the lid is opened I get this ajeeb [strange] smell...my appetite dies due to the smell and I do not want to eat anything.

Participant L recommended, "also there should be [a] variety in food for the patients. The food should not be spicy and it should not be tasteless. The entire food item tastes the same".

\section{Nurses' level}

For improvement at the nurses' level, most of the study participants provided some recommendations. These include: providing prompt responses, giving more time to patients, and presenting positive attitudes, in order to provide QNC.

Providing prompt responses: Many participants received delayed care, hence they highlighted the importance of providing prompt care to the patients. Participant B suggested that QNC means that that, Whenever a nurse is being called by the patient, the nurse should respond immediately. This is the most basic thing. If she/he come immediately and say I am busy I will be back after one minute, there is no issue. There should be a prompt response which is impossible here. 
Giving more time to patients: The study participants realized that nurses do not give enough time to the patients. They suggested that nurses should give more time to patients in order to establish good rapport with them.

Participant $\mathrm{H}$ mentioned that, "there are so many patients and I also observed that there is too much paper work involved". The participants felt that nurses spent more time in writing notes. Participant $\mathrm{F}$ recommended, "Nurses should give more time to the patient rather than writing in patients' files".

Presenting positive attitudes: In order to provide QNC the participants believed that nurses' positive attitude towards patients was very important. The patients also feel good when the nurses talk to them nicely and keep a smiling face. Participant B stated, "The most important care is that the nurses should be khushikhlaaq (polite). Whatever the patients say, he/she mshould temporarily accept it with a smile". While participant $\mathrm{C}$ mentioned that, "some of them are very good; just receiving even one or two smiles from them makes you feel much better".

This data reveals that prompt care, more time for patients, and the personality of nurses make an important contribution towards providing quality nursing care. It appears that nurses' clinical skills and knowledge are not the only factors that contribute to Quality Nursing Care; the nurses should also possess certain personal attributes, such as a polite demeanor, a smiling face, and a good sense of humor to make a significant impact on QNC.

\section{Discussion}

A simple definition of the phenomenon of quality in nursing care was difficult to find in the literature. Quality in healthcare is a complex, multi-faceted, and multi-dimensional phenomenon [7]. Healthcare professionals define quality in relation to patient outcomes, standards of practice, and predetermined criteria used to measure quality [8]. While, patients define quality with regard to interpersonal aspects of care, the way they are treated, and the promptness of the care provider [9].

In this study, it is important to note that most participants described QNC as receiving prompt care. This is mainly because the participants received delayed care from the nurses, except for the medications, which they received on time. Similar findings were reported by Henderson, Caplan, and Daniel (2004) who used a qualitative design to explore patient perspectives of what was important to make their hospital stay satisfactory and found that patients had to wait before receiving different aspects of care. However, medications were given at the right time [10].

Another finding in the current study was that some participants associated QNC with meeting expectations. Prior to hospitalization, patients generally have some expectations from the health care services. Once they experience the services, they may either be satisfied or dissatisfied with them [11]. Patient satisfaction is the most important indicator of high-quality health care and is used for the assessment of quality assurance and planning of health care [12]. In the current study, some participants compared their experiences of the previous stay with the current admission in the same private hospital and expressed that the level of care had declined as compared to the services provided ten to eleven years ago.

According to the participants in the current study, the characteristics of nurses appeared to play a key role in providing QNC.
The nurses who were perceived as providing QNC were supposed to have personal attributes such as kindness, politeness, having a smiling face and a good sense of humor. In addition, they should be competent in clinical skills and capable of providing pertinent information.

The most dominant attributes found in this study were a caring attitude, having a smiling face, and a sense of humor. The participants compared their previous hospitalization experiences with the current, and identified that the caring aspect in the nurses' behavior seemed to have decreased. The findings of the study reveal the importance of nurses maintaining a caring attitude in order to deliver QNC to patients. Similar findings have been highlighted in a previous study [13], in which patients perceived the nurses' professional care giving as the most important part of the quality of care.

\section{Conclusion}

Quality nursing care, the foundation of healthcare and QNC could have a positive recovery and well-being for patients. The characteristics of nurses, such as a positive and caring attitude including good clinical skills, are ingredients of QNC. Since, patients provide valuable information about quality care, involving them in the planning of healthcare could further be beneficial in improving and maintaining the quality of care.

\section{References}

1. Samina M, Gj Q, Tabish S, Samiya M, Riyaz R (2008) Patient's Perception of Nursing Care at a Large Teaching Hospital in India. Int J Health Sci (Qassim) 2: 92-100.

2. Zhao SH, Akkadechanunt T (2011) Patients' Perceptions of Quality Nursing Care in a Chinese Hospital. International Journal of Nursing and Midwifery 3: 145-149.

3. Al Momani M, Al Korashy H (2012) Patient experience of nursing quality in a teaching hospital in saudi arabia. Iran J Public Health 41: 42-49.

4. Schneider H, Palmer N (2002) Getting to the truth? Researching user views of primary health care. Health Policy Plan 17: 32-41.

5. Polit DF, Beck CT (2010) Essentials of nursing research: Appraising evidence for nursing practice (7th edn). Lippincott Williams \& Wilkins, Philadephia.

6. Todd NJ, Jones SH, Lobban FA (2012) "Recovery" in bipolar disorder: how can service users be supported through a self-management intervention? A qualitative focus group study. J Ment Health 21: 114-126.

7. Currie V, Harvey G, West E, Mckenna H, Keeney S (2005) Relationship between quality of care, staffing levels, skill mix and nurse autonomy: literature review. J Adv Nurs 51: 73-82.

8. Laal M (2013) Inpatient's Perspective of Nursing care; Affecting Factors. Social and Behavioral Sciences 84: 243-247.

9. Stichler JF, Weiss ME (2000) Through the eye of the beholder: multiple perspectives on quality in women's health care. Qual Manag Health Care 8: 1-13.

10. Henderson A, Caplan G, Daniel A (2004) Patient satisfaction: the Australian patient perspective. Aust Health Rev 27: 73-83.

11. Kulkarni MV, Dasgupta S, Deokel AR, Nayse (2011) Study of Satisfaction Of Patients Admitted In A Tertiary Care Hospital In Nagpur, National Journal Of Community Medicine 2: 37-39.

12. Schmidt LA (2003) Patients' perceptions of nursing care in the hospital setting. J Adv Nurs 44: 393-399.

13. Thorsteinsson LS (2002) The quality of nursing care as perceived by individuals with chronic illnesses: the magical touch of nursing. J Clin Nurs 11: 32-40. 